\title{
O técnico e as necessidades em saúde
}

\section{* Escola Nacional de Saúde Pública - FIOCRUZ - Rio de Janeiro}

\section{Luis David Castiel*}

This paper discusses the restraints that interfere on the activities of public health technical personnel on the identification of brazilians' health needs. It is suggested that centralized decision making taken by the State on health policies suits the interests of health entrepreneurs pharmaceutical and medical equipment industries. Actually, these groups restrict the way that public health technical personnel identify health needs, which are going to be insufficiently met by health institutions.

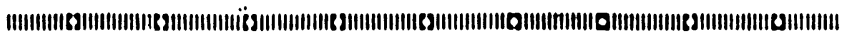

O presente artigo procura situar o papel do técnico do Setor Saúde na determinação das necessidades em saúde da população.

Para isso, as noçōes de "técnico" e "necessidade" são analisadas. A seguir, é considerada a relação deste profissional com a instituição de saúde no Brasil, bem como a dimensão do conhecimento técnico nas decisões.

Por fim, é discutida a participação do Estado na orientação das instituições de saủ de.

No processo de se estabelecer prioridades para políticas sociais, os setores de decisão recebem a influência de grupos com diferentes interesses. Esses interesses podem ser conflitivos e, por isto, produzem antagonismo entre as partes envolvidas. Estas, de modo geral, podem ser divididas em três se tores:

\section{- O SETOR DA DEMANDA}

Composto pelas populações que necessitam de atenção à saú de. É possível considerar três grandes grupos:

as classes de baixa renda - constituídas por grande parcela da população carente de atenção médica, procuram serviços de assistência médica da Previdência Social ou Medicina de Grupo; são alvo das ações preventivas do Ministério da Saúde; buscam atenção nos postos de saúde da rede municipal e/ou estadual das Secretarias de Saúde.

as classes médias - procuram utilizar a assistência médica da previdência social, mas também consomem serviços ligados a seguros privados de saúde. Além disso, buscam (progressivamente menos) o setor privado. as classes de alta renda - pequena minoria que, pre- 
dominantemente, paga diretamente pelos serviços do setor privado.

\section{- O SETOR DA OFERTA}

Constituido pelos seguintes componentes:

o sistema previdenciário de atenção médica.

- o Ministério da Saúde, responsável basicamente por açōes preventivas e controle de doenças.

a rede de Secretarias municipais e estaduais de Saúde, atuando tanto em ações preventivas como em assistência médica (através de postos de saúde).

a medicina privada, representada por policlínicas (medicina de grupo), casas de saúde, médicos particulares. O pagamento dos serviços pode ser direto (pelo usuário) ou indireto (pela Previdência Social).

\section{- O SETOR INDUSTRIAL}

Representado pela indústria farmacêutica e pela indústria de equipamentos.

Estes componentes e suas interações merecem discussð̃es específicas, mas que escapam ao objetivo deste trabalho. $O$ presente artigo trata do técnico do Setor Saúde - situado do lado da oferta, ocupando cargos na Previdência Social, no Ministério da Saúde, na rede das Secretarias de Saúde. Uma de suas possíveis funções seria participar na determinação das prioridades em políticas sociais. Uma fase crucial neste processo é a definição das necessidades das populações. Assim, em função destas prioridades, os recursos seriam distribuídos buscando satisfazer às necessidades definidas a priori. O processo seguiria uma racionalidade técnica, considerando-se as restrições impostas pelas contingências.

Antes, porém, de aprofundar o problema, é preciso estabelecer melhor as "categorias" desta discussão: as noções de "técnico" e "necessidade social".

De maneira geral, o termo "técnico" refere-se ao indivíduo que possuiria certa habilidade e/ou conhecimento específico sobre determinado assunto. Estas prerrogativas the confeririam a "autoridade" para avaliar e julgar questões pertencentes à sua área de atuação/conhecimento. Poderia ser considerada aqui a idéia de experto ("expert"), onde esta autoridade seria mais sólida em virtude da prática e da experiência adquirida ao longo do tempo. Entretanto, não parece ser necessário, para ser técnico, que o indivíduo seja um "expert".

De qualquer maneira, não importa agora detalhar como o indivíduo adquire tal status (seja através de treinamento, capacitação acadêmica, experiência), mas é relevante destacar que o técnico possuiria uma legitimidade para intervir, baseada em sua "autoridade". Illich ${ }^{6}$ sugere a expressão 
* E interessante observar que a relação entre posiçâo/capacitação/ prestígio pode não ter uma correspondência de proporçōes equilibradas. Nem sempre o grau de prestigio combina adequadamente com a posição e/ou competência do técnico. "biocrata" para designar este tipo de técnico - o tecnocrata do setor saúde.

De modo geral, qualquer profissional pode desempenhar este papel, dependendo, para isto, de três condições:

1a) de sua posição funcional na instituição de saúde;

2a) de sua capacitação técnica para estar em tal posição;

3ạ) do prestígio que possui sua posição e/ou capacitação no meio onde atua (ou mesmo fora dele)*

Assim, profissionais da área de planejamento e administração em saúde, das ciências biomédicas, das ciências sociais e da área de saneamento ambiental podem ser "técnicos". Para isto, devem preencher, satisfatoriamente, as con. dições mencionadas.

Por outro lado, definir necessidade social é uma tarefa complexa. Existem correntes com distintas concepções de necessidade. No Setor Saúde do estado capitalista, parece predominar a concepção naturalista do sujeito. Faleiros ${ }^{4}$, sugere que, de acordo com esta concepção, 'haveria uma natureza humana, independente da sociedade e em função da qual as organizações econômicas, sociais e políticas estariam estabelecidas. Este paradigma vai ainda mais longe quando afirma que a sociedade deveria ter resposta às necessidades dessa natureza, que seria o fim último de toda a organização social (. . .). Segundo essa concepção naturalista é a FALTA que caracteriza a necessidade. Seja ela a necessidade de sobreviver, seja a de desenvolver-se. A 'fal ta de algo' em uma natureza ideal e genérica".

Pode-se identificar esta concepção na "taxonomia da necessidade social", desenvolvida por Bradshaw ${ }^{2}$, onde são estabelecidos quatro tipos de necessidade:

1) "Normativa: onde um padrão desejável é estabelecido e comparado com o padrão do que existe na realidade - se um indivíduo ou grupo não se inclui no padrão desejável, então são considerados como estando em necessidade.

2) Sentida: neste caso, a necessidade corresponde à aspiração ("want") (. .). Está limitada à percepção do indivíduo.

3) Expressa (ou Demanda): é a necessidade sentida transformada em ação. É medida através da população que busca serviços.

4) Comparativa: este tipo de necessidade é o resultado da comparação com as características daqueles que recebem serviços. Se pessoas com características similares não os recebem, então estão em necessidade".

Em relação às necessidades em saúde, $\mathrm{Cooper}^{3}$, diz que "necessidades são aquelas demandas que, na opinião do médico, requerem atenção médica". Esta definição assemelhase à "necessidade expressa" de Bradshaw. Entretanto, Coo- 
per sugere que a necessidade pode, muitas vezes, ser uma questão de "modismo" médico (como exemplo, cita a remoção das amígdalas). É importante acrescentar que a maneira como os proventos médicos são estipulados pode interferir no estabelecimento da demanda. Em linhas gerais, a remuneração do trabalho médico pode ser feita mediante unidades de serviço, salários ou capitação*. É notória, por exemplo, a crítica que sofre o INAMPS pelos efeitos do pagamento por unidades de serviço na qualidade de sua atenção médica.

Além disso, Matthew ${ }^{7}$ coloca a questão de que um indivíduo só está em necessidade de assistência médica se houver alguma medida ou terapêutica médica efetiva e aceitável para sua doença.

Parte da literatura especializada explora a conhecida teoria do "iceberg". Nesta situação, a parte submersa indicaria a magnitude dos indivíduos em estado de necessidade, mas que não chegam a receber serviços (NECESSIDADE LATENTE). A parte emersa representaria a parte da população que efetivamente busca assistência (NECESSIDADE MANIFESTA OU DEMANDA). Um dos objetivos dos serviços é o de atingir a população que necessita, mas não recebe atenção médica.

Todavia, parecem existir evidências de que a assistência à saúde não se mostra adequada nem mesmo às populações que chegam aos serviços**. Apesar de parecer um truísmo, a determinação das necessidades não leva obrigatoriamente ao atendimento destas necessidades.

Existem diversos fatores que poderiam explicar esta situação. Desde problemas na organização da atenção médica até a influência da distribuição da renda na saúde das populações. Porém, neste artigo, o foco é colocado sobre a responsabilidade dos técnicos do setor saúde diante desta situação. A hipótese a discutir seria que a determinação das necessidades não chega a ser feita de fato. Apesar da sua importância, não cabe desenvolver a discussão conceitual de necessidade. Importa, sim, considerar um aspecto que parece ocorrer nas instituições do setor saúde brasileiro: a dissociação entre estrutura e objetivos manifestos em relação aos resultados atingidos.

A estrutura institucional estaria organizada com base na "racionalidade" das burocracias do estado capitalista. Teria (entre outras funções) o objetivo de incluir o "conhecimento técnico" como suporte às decisões. No entanto, via de regra, isto parece não ocorrer, uma vez que o processo decisório se dá de forma predominantemente centralizada. Desde modo, parece existir um descompasso: a instituição estaria organizada numa racionalidade técnica sem conexão com a forma centralizada da tomada das decisões. Todavia, este "conhecimento" poderia ser incluído, caso servisse para validar questões decididas noutras instâncias.
* Na capitação, o médico recebe pelo número de individuos que estão inscritos em sua lista de pacientes, independente da quantidade de ações médicas que estes demandem. Este é o modelo adotado pelo Sistema Nacional de Saúde inglês para a remuneração do "General practitioner". Ver a este respeito $A B E L-S M I T H, B$. 'Value for money in health services'. London, Heinemann, 1976. p. 58.76.

**Ver a este respeito CORDEIRO, $H$. "A qualidade de vida urbana e as condições de saúde" - $O$ caso do Rio de Janeiro. Rio de Janeiro, 1981 (mimeo.). 
* Existe nos paises escandinavos e na Grä-Bretanha uma forma de interpor um elemento entre $o$ técnico e o leigo. Trata-se do "OMBUDSMAN" - um representante oficial designado para investigar as queixas do cidadão contra instituiçōes governamentais que podem estar in fringindo os direitos do individuo. No Brasil, procura-se criar o "Procurador Geral do Povo" que teria as funçōes mencionadas. A questão é determinar o grau de representatividade do

“OMBUDSMAN" em relação aos interesses da população.
A hipótese cogitada sugere que a insuficiente participação técnica nas decisões deve, de alguma forma, orientar a congruência com que o técnico avaliará as necessidades sociais. Mas, no momento em que houver maior participação do técnico nas decisões, seu desempenho refletirá melhor as necessidades em saúde da população?

Antes de tudo, é importante especificar o tipo e o teor do saber do técnico. Será que todas as áreas de conhecimento necessitam indiscriminadamente de técnicos? Uma crítica feita à medicina moderna refere-se à "medicalização da sociedade". Neste caso, diversos fenômenos da existência humana seriam englobados pelo saber médico. $O$ envelhecimento, por exemplo, necessitaria de um especialista para "tratá-lo". Freidson 5 indaga em quais setores o saber do técnico ("expertise") é absolutamente necessário e em quais não é (...). "E, caso seja necessário, quais são suas limitações?". Freidson postula que "a prática, exercício ou aplicação do saber do técnico é analiticamente distinta do próprio saber (. . ) e pode estar, cada vez mais, em perigo de ser usada como máscara para privilégio e poder do que, como se apresenta, um modo de progredir no interesse comum". Quiçá o déficit da Previdência Social tenha em alguma de suas causas algo relacionado a esta postulação.

Além disso, a avaliação das necessidades possui úm componente subjetivo, isto é, baseada em juízos de valor. Assim, existe possibilidade de que a percepção do técnico não seja movida tão somente por critérios objetivos e manifestos. Não cabe, por certo, analisar as motivações inconscientes que intermediam as avaliações. Mas, para controlar o grau de subjetivismo nos julgamentos, estes critérios devem ser explicitados e discutidos não apenas no meio restrito das decisões. Entretanto, a autoridade do técnico pressupõe, "logicamente", sua inequívoca habilidade para julgar e sugerir prioridades para ações de saúde. Essa capacidade é mistificada por uma aura de competência que o abstém de tornar explícitos os critérios de julgamento, por vezes não somente técnicos*.

Além disso, viu-se que o modo de pagamento do ato médico pode determinar suas características. É possível considerar, também, a instituição que paga ao técnico como capaz de dirigir o conteúdo de sua atividade. Assim, é preciso analisar os objetivos e interesses da instituição e de sua definição da realidade. Mas, que realidade seria essa? Berger \& Luckmann" encaminham esta questão dizendo que "a realidade é socialmente construída. Mas as definições estão sempre corporificadas, isto é, indivíduos concretos e grupos de indivíduos servem como definidores da realidade. Para entender o estado do universo socialmente construído em dado momento, ou sua modificação no decorrer do tempo, precisa-se entender a organização social que permite aos definidores realizar suas definições". 
Seria uma tarefa desproporcional aos objetivos deste trabalho desenvolver uma análise da organização social brasileira. Porém, é possível localizar esta questão, ao se considerar que é o Estado quem organiza e determina a atuação do Setor Saúde.

A intervenção do Estado resulta da confluência de diversos interesses, mas sua função básica é a de manter as condições para a sustentação do sistema econômico. Assim, a organização dos setores responsáveis por definir as necessidades da população (e atendê-las) vai, em última instância, depender do "modelo econômico" adotado.

Navarro ${ }^{8}$, baseado em Gramsci diz que "o Estado dirige e se envolve na maioria das esferas da vida política, social e econômica, e a influência ideológica do aparelho de estado transcende muito ao setor geralmente referido como o setor público". Navarro inclui, no "sentido Gramsciano", "todas as instituições afetadas pelo aparelho de estado, não apenas a medicina ou outras instituições responsáveis pela provisão de outros serviços, mas, também, o mundo acadêmico, os meios de comunicação, etc". Além disso, sugere que "o processo de concentração econômica e sua concomitante industrialização determinam o modelo de produção e distribuição em medicina que reproduz as características do processo geral de produção econômica e distribuição, isto é, especialização, concentração, urbanização e orientação tecnológica da medicina. A natureza da medicina, então, e sua relação com o processo geral da produção determinam bastante suas características". Navarro conclui dizendo que "esta posição no interior do processo de produção explica sua função que é de solucionar o insolúvel - o mal-estar ("diswelfare") e as disfunções criadas por este mesmo processo de produção".

Assim, dentro do processo geral de produção, os fatores que orientam o desempenho dos técnicos teriam a mesma origem dos que determinam a organização do setor saúde. Neste caso, as indústrias farmacêuticas e de equipamentos médicos, bem como os empresários em saúde* interferem, decisivamente, na ação do Estado no Setor Saúde.

Diante do presente quadro político-econômico e institucional, o técnico ficaria circunscrito a uma atuação que não pode contrariar a hegemonia dos grupos citados. Desta forma, tal atuação não chegaria a detectar, de fato, as necessidades em saúde das populações. já que estas dificilmente seriam atendidas. Nesse sentido, o papel do técnico tende a ser sobretudo o de validar as decisões políticas, orientadas pelos interesses mencionados.

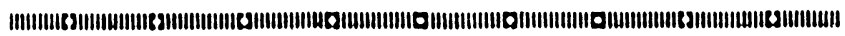

Este artigo discute as limitações do técnico do Setor Saúde na identificação das necessidades sanitárias da
* Donos de laboratórios, policlínicas, casas de saúde. 
população brasileira. Sugere-se que a centralização das decisões em politicas de saúde tomadas pelo Estado corresponde aos interesses dos empresários da Saúde, das indústrias farmacêuticas e de equipamentos médicos. Assim, a interferência destes grupos condiciona a forma insuficiente como o técnico identifica tais necessidades, já que estas serão atendidas precariamente pelas instituiçōes de Saúde.

\section{REFERÊNCIAS BIBLIOGRÁFICAS}

1. BERGER, P. \& LUCKMANN, T. The social construction of reality. London, Penguin Books, 1971.

2. BRADSHAW, J. A taxonomy of social need. In: MACLACHLAN, F. (Org.) Problems and progress in medical care. London, Oxford University Press, 1972.

3. COOPER, M.H. Rationing health care. London, Croon Helm., 1975.

4. FALEIROS, V. de P. A politica social do estado capitalista. São Paulo, Cortez, 1980.

5. FREIDSON, E. Profession of medicine. New York, Dood Mead \& Co., 1970.

6. ILLICH, I. Medical nemesis: the expropriation of heal th. New York, Randon House, 1976.

7. MATTHEW, G.K. Measuring need and evaluation services. In: MCLAHLAN, G. (Org.) Portfolio for health. London, Oxford University Press, 1971.

8. NAVARRO, V. Medicine under capitalism. New York, Neale Watson. 1976. 